Article

\title{
Effects of Pre-Cooling on Thermophysiological Responses in Elite Eventing Horses
}

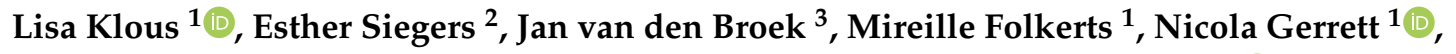 \\ Marianne Sloet van Oldruitenborgh-Oosterbaan ${ }^{2}$ and Carolien Munsters $2,4, * \mathbb{D}$ \\ 1 Department of Human Movement Sciences, Faculty of Behavioural and Movement Sciences, \\ Vrije Universiteit Amsterdam, Amsterdam Movement Sciences, Van der Boechorststraat 7-9, \\ 1081 BT Amsterdam, The Netherlands; 1.klous@vu.nl (L.K.); m.a.folkerts@vu.nl (M.F.); \\ n.m.gerrett@vu.nl (N.G.) \\ 2 Department of Clinical Sciences, Faculty of Veterinary Medicine, Utrecht University, Yalelaan 112, \\ 3584 CM Utrecht, The Netherlands; e.w.siegers@uu.nl (E.S.); m.sloet@uu.nl (M.S.v.O.-O.) \\ 3 Department of Population Health Sciences, Utrecht University, Yalelaan 7, 3584 CL Utrecht, The Netherlands; \\ j.vandenBroek@uu.nl \\ 4 Moxie Sport Analysis \& Coaching, Looieind 1, 5469 Erp, The Netherlands \\ * Correspondence: carolien@munsters.nl; Tel.: +31-6125-097-19
}

Received: 15 July 2020; Accepted: 7 September 2020; Published: 16 September 2020

check for updates

Simple Summary: Horses have a high metabolic capacity for exercise, producing a great deal of heat, and have a small surface area for heat loss. Under limited circumstances, the regulation of heat loss (i.e., across the respiratory tract and by the evaporation of sweat) means heat build-up in the body is reduced. Thermoregulation can be assisted by cooling the horses down to safely perform exercise in thermally challenging environments. The present study showed that pre-cooling (i.e., cooling between the warm-up and exercise performance) slightly reduced the rise in rectal, shoulder and rump skin temperatures of ten international eventing horses during moderately intense canter training in moderate environmental conditions. During the canter training, heart rate, sweat rate and sweat composition were unaffected by pre-cooling. The pre-cooling strategy chosen here was cold-water rinsing for a short period of time ( $\sim 8 \mathrm{~min})$. Considering the limited time and space at equestrian events, such a pre-cooling strategy could easily be implemented. Reducing heat strain by pre-cooling may potentially improve equine welfare during events.

Abstract: In this study, we examined the effects of pre-cooling on thermophysiological responses in horses exercising in moderate environmental conditions (average wet bulb globe temperature: $18.5 \pm 3.8^{\circ} \mathrm{C}$ ). Ten international eventing horses performed moderate intensity canter training on two separate days, and were either pre-cooled with cold-water rinsing $\left(5-9{ }^{\circ} \mathrm{C}\right.$ for $8 \pm 3 \mathrm{~min}$; cooling) or were not pre-cooled (control). We determined velocity (V), heart rate (HR), rectal temperature $\left(\mathrm{T}_{\mathrm{re}}\right)$, shoulder and rump skin temperature $\left(\mathrm{T}_{\text {shoulder }}\right.$ and $\left.\mathrm{T}_{\text {rump }}\right)$, plasma lactate concentration (LA), gross sweat loss (GSL), and local sweat rate (LSR), as well as sweat sodium, chloride and potassium concentrations. The effect of pre-cooling on $\mathrm{T}_{\mathrm{re}}$ was dependent on time; after $20 \mathrm{~min}$ of exercise the effect was the largest (estimate: 0.990, 95\% likelihood confidence intervals (95\% CI): 0.987, 0.993) compared to the control condition, resulting in a lower median $\mathrm{T}_{\mathrm{re}}$ of $0.3^{\circ} \mathrm{C}$. Skin temperature was also affected by pre-cooling compared to the control condition $\left(\mathrm{T}_{\text {shoulder }}:-3.30^{\circ} \mathrm{C}, 95 \% \mathrm{CI}:-3.739\right.$, $\left.-2.867 ; \mathrm{T}_{\text {rump }}:-2.31^{\circ} \mathrm{C}, 95 \% \mathrm{CI}:-2.661,-1.967\right)$. V, HR, LA, GSL, LSR and sweat composition were not affected by pre-cooling. In conclusion, pre-cooling by cold-water rinsing could increase the margin for heat storage, allowing a longer exercise time before a critical $\mathrm{T}_{\mathrm{re}}$ is reached and, therefore, could potentially improve equine welfare during competition. 
Keywords: horses; pre-cooling; rectal temperature; sweat composition; sweat rate

\section{Introduction}

Half the body mass of horses consists of skeletal muscle mass, and consequently, the mass-specific heat load for exercising horses is two- to three-fold higher than for exercising humans, while horses have a low surface-area-to-body mass ratio for heat dissipation ( 1:100) compared to humans ( 1:40) [1-3]. During high-intensity exercise, like eventing, the discrepancy between heat production and dissipation stresses the equine thermoregulatory system $[1,2,4,5]$. Only under limited circumstances (i.e., low environmental temperature, low exercise intensity, and short duration exercise) does the heat dissipation across the respiratory tract and from the evaporation of sweat from the skin surface prevents thermal strain in horses. However, in most environmental conditions, the potential to develop heat strain during exercise increases significantly because evaporation is impeded $[1,4,5]$. Therefore, most horses are at risk of exercise-induced hyperthermia when exercising through rapidly increasing core temperature $[1,4]$.

To safely perform exercise in challenging environmental conditions, it is beneficial to assist the thermoregulation of the horse by providing cooling [6]. The need for cooling strategies evolved from ensuring the welfare of horses during competitions, commonly held during summer in hot and/or humid environmental conditions. Due to their sensitive gastrointestinal tract, horses are usually cooled externally (i.e., cold-water rinsing) rather than internally (i.e., drinking icy water). In the best case scenario, a cooling strategy lowers core temperature, which is considered as the critical determinant of performance in the heat [7]. However, it is more realistic to expect reductions in skin temperature utilizing external cooling strategies.

Lowering the skin temperature could be beneficial by increasing the temperature gradient between the skin and environment, which facilitates convective heat loss. Several post-cooling studies (i.e., cooling after exercise) have shown an effect of cooling on skin and even core temperatures [6,8-10]. Cooling can also be provided prior to exercise (pre-cooling) to increase the margin for heat storage by decreasing pre-exercise core and skin temperatures [11]. In this way, performance may even be influenced, compared to post-cooling. To provide the fastest cooling rate, human research supports the use of cold-water immersion [12,13]. For horses, cold-water immersion is not practical; however, considering the large convective cooling capacity of water, as much surface as possible could be exposed to cold water to still show good effects $[6,8]$.

Eventing is an equine discipline consisting of dressage, cross-country and show jumping on one or three consecutive days. Competitions are held at the national and international level (three-day events), of which the latter ranges from the Concours Complet International level 1 (CCI1*) to the highest level 5 (CCI5*; including the Olympic Games). At the international level, on the first day, a dressage test is performed (a 6-min low intensity technical skills test). On the following day, horses perform a cross-country test, which consists, at the highest level, of a track up to 6270 m including 40 jumping efforts that has to be completed at a velocity (V) of $570 \mathrm{~m} / \mathrm{min}(\sim 9.5 \mathrm{~m} / \mathrm{s}$; taking up to $12 \mathrm{~min}$ in total). On the third and final day, a show jumping test is performed. Considering the physically challenging cross-country test $[2,14,15]$, pre-cooling may be particularly beneficial there. In a recent practical recommendation for the Olympic Games in Tokyo, The Fédération Equestre Internationale (FEI) already recommends to pre-cool eventing horses before the cross-country test under particular environmental conditions (wet bulb globe temperature (WBGT) $>28^{\circ} \mathrm{C}$ ) [16]. However, to date, no scientific study backs up this recommendation and practical pre-cooling methods for horses have not been studied in-depth.

Equine research has shown that the sudomotor response is the most effective way of losing heat during exercise [5]. The apocrine sweat glands that cover the horse's entire body surface excrete a sweat solution that is slightly hypertonic to blood $[17,18]$. Producing large volumes of this hypertonic sweat may therefore have serious implications on overall electrolyte losses. Core temperature is the 
main driver of sweat production and skin temperature has a modifying effect [19]. The modifying effect of skin temperature is stimulating when skin temperature is high and inhibiting when skin temperature is low. Pre-cooling might lower core and/or skin temperature in horses as it does in humans [20], possibly resulting in lower sweat rates and electrolyte losses. This could lead to the conservation of important electrolytes, alongside an attenuated core and/or skin temperature.

The main objective of this study was to evaluate the effect of pre-cooling on thermophysiological responses in horses. We hypothesized that pre-cooling by cold-water rinsing would cause a lower heart rate $(\mathrm{HR})$, rectal $\left(\mathrm{T}_{\mathrm{re}}\right)$ and skin temperature during exercise. Secondly, we hypothesized that the sweat rate and the excretion of electrolytes in sweat would be reduced during exercise following pre-cooling.

\section{Materials and Methods}

\subsection{Participants}

In setting up the study and related report, the STROBE guidelines were followed whenever possible [21]. The Animal Ethics Committee of Utrecht University approved all procedures (reference number: 5204-1-3, approval date: 19 June 2019). We also obtained the individual horse owner's informed consent. Ten international Warmblood eventing horses (six geldings, four mares; age: $8.4 \pm 2.6$ years; body mass: $578 \pm 36 \mathrm{~kg}$, height at withers $1.69 \pm 0.04 \mathrm{~m}$, and body mass index (BMI): $203.7 \pm 8.2 \mathrm{~kg} / \mathrm{m}^{2}$ ) participated in this study. Horses were in full training according to their competition level: six horses performed at the CCI1*-2* level (novice horses: age $6.5 \pm 0.5$ years) and four horses performed at the $\mathrm{CCI} 4^{*}-5^{*}$ level (advanced horses: age $11.3 \pm 1.8$ years). All horses were in training for several years (3-10 years) and had at least 5 months of specific conditional training up to their competition level. As the horses were all competing at high international levels in eventing, these horses were assumed to have a high fitness level. During the study (mid-summer in The Netherlands), all horses were in their summer coat $(<5 \mathrm{~mm})$. The horses were ridden by their usual rider, housed in individual stables, provided water ad libitum, and fed an individual diet.

\subsection{Design}

The protocol consisted of a moderate intensity canter training on two separate days (with two days in between) in July 2019 in the Netherlands. All canter training sessions were performed on the same 1300-m sand-based track. This type of training was selected to prevent interfering with horses' individual competition schedules. A cross-over design was used. Horses performed the same moderate intensity canter training on two separate days and were pre-cooled on one occasion (cooling) or not (control). The horses were randomly selected for the cooling or control treatment on the first day and had the other treatment on the second day. Horses were tested at the same time of day $( \pm 1 \mathrm{~h})$ in fixed pairs.

The warm-up consisted of a 10-min walk, 10-min trot, 3-min canter $(5 \mathrm{~m} / \mathrm{s})$ and 3-min walk. Immediately after warming-up, the horses were pre-cooled using $60 \mathrm{~L}$ of cold-water $\left(5-9^{\circ} \mathrm{C}\right)$. Cold-water was used because it was previously shown to be an effective post-cooling strategy (water temperature range $\left.\sim 5-9{ }^{\circ} \mathrm{C}[6,8-10]\right)$. Water was continuously poured $(8 \pm 3 \mathrm{~min})$ over the horse's entire body surface by two researchers with $10 \mathrm{~L}$ buckets. As there is limited time and space to pre-cool the horses at equestrian events, this short and practical strategy was chosen.

The canter training started immediately after pre-cooling and consisted of two 4.5-min canter bouts with a 2-min walk in between and ended with a 10-min walking recovery. Novice horses aimed to canter at $6.7 \mathrm{~m} / \mathrm{s}$ and advanced horses at $7.5 \mathrm{~m} / \mathrm{s}$. The exercise intensity was chosen in accordance with their riders and in alliance with their normal conditional training work (performed by experienced elite eventing riders at the $\mathrm{CCI}^{*}$ level) and on the evaluation of previous conditional training sessions ( $\mathrm{HR}$ and $\mathrm{V})$ of these horses. The chosen velocities were considered as moderate intensity $\left(<\mathrm{V}_{\mathrm{LA2}}[22]\right)$ for these horses. 


\subsection{Measurements}

To calculate BMI (i.e., the ratio of height and body mass), the height of the withers was determined for each horse. Body mass of the horses and mass of the tack including the saddle pads and protection boots were measured before saddling and after the canter training (horse scale: custom-made, Breinler International; platform scale: SATEX 34 SA-1 250, Weegtechniek Holland). Feces produced between the first and second weighing moment were collected and weighed. WBGT (QuesTemp 32, $3 \mathrm{M}$ ) was obtained before the start of each run. The horses were equipped with a HR monitor with a built-in GPS system at $12 \mathrm{~Hz}$ (V800, Polar). A T re sensor (B10014, MSR) was inserted to a depth of $25 \mathrm{~cm}$ into the rectum with the datalogger attached to the base of the tail. Skin temperature sensors (i-Button $1922 \mathrm{~L}$, Maxim Integrated) were attached to the shoulder and rump ( $\mathrm{T}_{\text {shoulder }}$ and $\mathrm{T}_{\text {rump}}$; Figure 1) [23] with removable glue (Bison Kit, Bison International). Gross sweat loss (GSL) was calculated using Equation (1):

$$
\mathrm{GSL}=\left(m_{\text {horse-post }}-m_{\text {horse-pre }}\right)+\left(m_{\text {tack-post }}-m_{\text {tack-pre }}\right)-m_{\text {feces }}
$$

where $m$ represents mass $(\mathrm{kg})$. Local sweat rate (LSR) was assessed by the absorbent patch technique [24]. Three custom-made absorbent patches $\left(25 \mathrm{~cm}^{2}\right)$ were attached to the neck with removable glue (Figure 1 ). LSR was calculated according to Equation (2):

$$
\operatorname{LSR}=\left(m_{\mathrm{wet}}-m_{\mathrm{dry}}\right) / \mathrm{t} / \mathrm{SA} .
$$

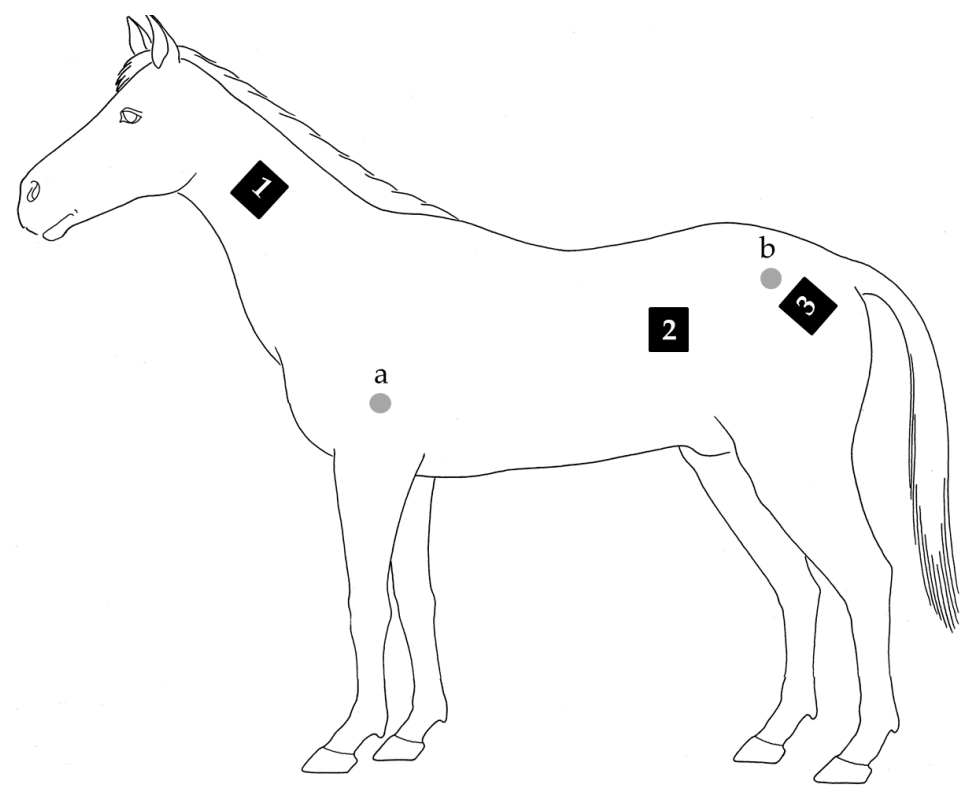

Figure 1. Measurement locations of the skin temperature sensors, represented by the grey cycles ( $\mathrm{a}=$ shoulder; and $\mathrm{b}=$ rump), and absorbent sweat patches, represented by the black rectangles ( 1 = neck; 2 = barrel; and 3 = rump).

Here, $m_{\text {wet }}$ refers to mass of the wet patch $(\mathrm{g})$ after the experiment, $m_{d r y}$ to the dry mass $(\mathrm{g})$, $\mathrm{t}$ represents application time $(\mathrm{min})$ and SA is the surface area $\left(\mathrm{m}^{2}\right)$. Sweat sodium, chloride and potassium were determined by ion-selective electrodes (Cobas 8000, Roche Diagnostics) (Table 1) after centrifuging $(1500 \times g$ for $5 \mathrm{~min})$ the patches in sealed plastic tubes. The patches were analyzed for background concentrations and corrections were made accordingly (sodium $-7.9 \mathrm{mmol} / \mathrm{L}$ and chloride $-6.6 \mathrm{mmol} / \mathrm{L}$ ). No correction was needed for potassium. Blood samples were taken from the jugular vein within $30 \mathrm{~s}$ after the last canter bout and again after $10 \mathrm{~min}$ of recovery. Plasma lactate concentration $\left(\mathrm{LA}_{0}\right.$ and $\left.\mathrm{LA}_{10}\right)$ was determined with a portable hand-held lactate measurement device (Lactate Pro2, Arkray Inc.) [25]. 
Table 1. Accuracy of the analyzers for the electrolyte concentrations in sweat.

\begin{tabular}{cccc}
\hline Component & LOD $(\mathbf{m m o l} / \mathrm{L})$ & CV $\mathbf{( \% )}$ & Sample Volume $(\mu \mathrm{L})$ \\
\hline Sodium & 0.4 & $<1.0$ & 15 \\
Chloride & 0.4 & $<2.2$ & 15 \\
Potassium & 0.2 & $1.0-1.3$ & 15 \\
\hline
\end{tabular}

LOD: Limit of detection; CV: coefficient of variation.

\subsection{Statistical Methods}

Continuous recorded data were transformed to 1-min averages. To check whether the normality assumption was reasonable, we made normality probability plots of the residuals. If the normality assumption did not hold, the data was log-transformed to obtain a normal distribution (transformed $\mathrm{T}_{\mathrm{re}}, \mathrm{LA}_{0}$, and $\mathrm{LA}_{10}$ ). If data were transformed, the statistical outcome medians rather than the means were reported [26]. The data of the training session following pre-cooling or control were analyzed. $\mathrm{HR}, \mathrm{T}_{\mathrm{re}}, \mathrm{T}_{\text {shoulder }}$, and $\mathrm{T}_{\text {rump }}$ were analyzed using a mixed effect model with horse as a random effect and with cooling, sex, age, BMI, WBGT, day, time, and time $x$ cooling interactions as fixed effects. This was called the starting model. Due to the strong relationship between the competition level and age, only age was included in the starting model. Model reduction was done using Akaike's information criterion (AIC) using R (R: A Language and Environment for Statistical Computing, 2019). The model for which there was no further reduction possible was taken as the final model, and the remaining factors were considered important [27]. The 95\% profile likelihood confidence intervals $(95 \% \mathrm{CI})$ were reported where there was an important effect.

Mixed effect models were used to analyze V, $\mathrm{LA}_{0}, \mathrm{LA}_{10}, \mathrm{GSL}$, and LSR, as well as sweat sodium, chloride, and potassium concentrations with random horse effects and sex, age, BMI, WBGT, day, and pre-cooling as fixed effects (i.e., the starting model). Model reduction was again done using AIC in IBM SPSS Statistics 26.0.

\section{Results}

The control condition HR data of one horse were missing due to technical issues. In addition, $\mathrm{T}_{\text {shoulder }}$ data of two horses (cooling: 1; and control: 1) was missing because the sensor fell off during the training. As data collection took place on two separate days, differences in WBGT occurred (day 1: $15.9 \pm 0.4{ }^{\circ} \mathrm{C}$; day 2: $21.1 \pm 3.9^{\circ} \mathrm{C}$ ). The velocities did not differ between cooling and control conditions (Table 2).

Table 2. Mean and standard deviation of the performed velocities of ten international eventing horses in the Netherlands during the warm-up and training following pre-cooling (cooling) or not (control) (average wet bulb globe temperature: $18.5 \pm 3.8^{\circ} \mathrm{C}$ ). The stages are chronologically ordered from top to bottom.

\begin{tabular}{cccc}
\hline \multirow{2}{*}{ Stage } & \multirow{2}{*}{ Gait } & \multicolumn{2}{c}{ V $(\mathrm{m} / \mathrm{s})$} \\
\cline { 3 - 4 } & & Cooling & Control \\
\hline \multirow{3}{*}{ Warm-up } & Walk & $1.6 \pm 0.2$ & $1.6 \pm 0.1$ \\
& Trot & $3.3 \pm 0.3$ & $3.3 \pm 0.3$ \\
& Canter & $4.6 \pm 1.2$ & $4.8 \pm 1.4$ \\
& Walk & $0.7 \pm 0.3$ & $0.7 \pm 0.4$ \\
\hline \multirow{2}{*}{ Pre-cooling } & & Yes & No \\
\hline \multirow{2}{*}{ Canter training } & Canter I & $7.0 \pm 0.1$ & $7.1 \pm 0.2$ \\
& Canter II & $6.8 \pm 2.2$ & $6.9 \pm 0.7$ \\
& Recovery & $1.6 \pm 0.0$ & $1.6 \pm 0.1$ \\
\hline
\end{tabular}

V: velocity; Canter I: first 4.5-min canter bout; Canter II: second 4.5-min canter bout.

\subsection{Heart Rate}

Age, day, and time had an effect on HR during training. Older horses showed on average a higher HR (3 bpm, 95\% CI: 2.197, 4.062). HR was lower on the second compared to the first day (estimate: $-6 \mathrm{bpm}, 95 \% \mathrm{CI}:-10.333,-2.555)$ and there were time effects. Pre-cooling showed a tendency to an average HR decrease ( -4 bpm, 95\% CI: -7.738 , 0.039) (Figure 2, Supplementary Table S1). 

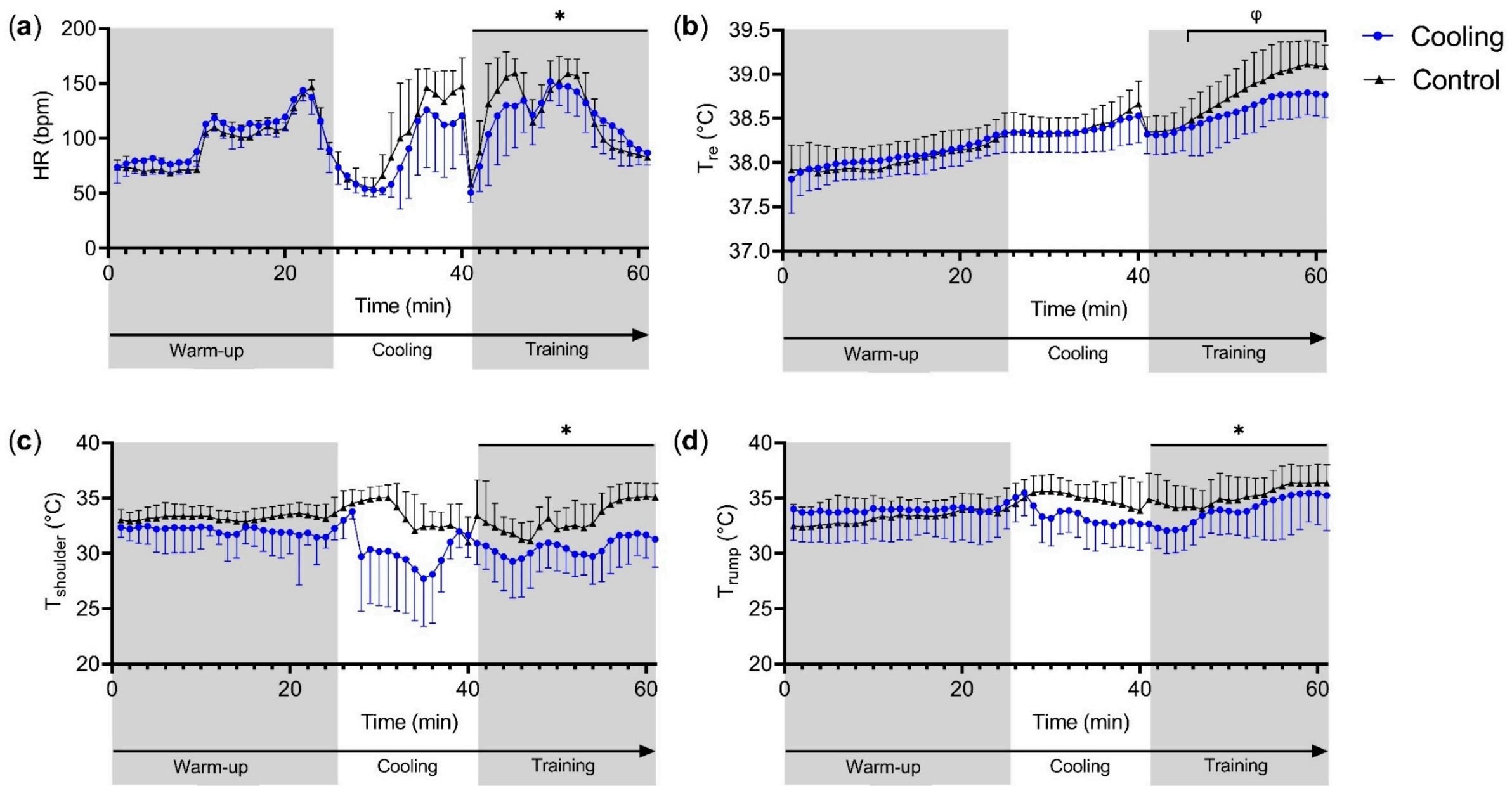

Figure 2. Mean and standard deviation of the physiological responses of ten international eventing horses in the Netherlands (average wet bulb globe temperature: $18.5 \pm 3.8^{\circ} \mathrm{C}$ ). The data are shown for the warm-up and canter training with either pre-cooling (cooling) or not (control) in between. (a) Heart rate (HR); (b) rectal temperature $\left(\mathrm{T}_{\text {re }}\right)$; (c) shoulder skin temperature $\left(\mathrm{T}_{\text {shoulder }}\right)$; and (d) rump skin temperature $\left(\mathrm{T}_{\text {rump }}\right) .{ }^{*}$ Denotes an effect of cooling. ${ }^{\varphi}$ Denotes an interaction effect of time $x$ cooling. 


\subsection{Rectal Temperature}

Every degree increase in WBGT increased median $\mathrm{T}_{\mathrm{re}}$ by $1.00^{\circ} \mathrm{C}(95 \% \mathrm{CI}: 1.0008,1.0012)$. At the second and hotter testing day, the median $\mathrm{T}_{\text {re }}$ was $0.99{ }^{\circ} \mathrm{C}$ higher $(95 \% \mathrm{CI}: 0.994,0.997)$. There were time effects and interactions of time x pre-cooling effects. From $6 \mathrm{~min}$ on in training, pre-cooling attenuated the increase in $\mathrm{T}_{\text {re }}$ compared to the control condition, with the largest effect after $20 \mathrm{~min}$ : $\mathrm{T}_{\text {re }}$ was $38.9 \pm 0.3^{\circ} \mathrm{C}$ in horses that were pre-cooled and $39.1 \pm 0.2^{\circ} \mathrm{C}$ in the control condition $(0.990$, $95 \%$ CI 0.987, 0.993) (Figure 2, Supplementary Table S2).

\subsection{Shoulder Skin Temperature}

Sex, age, WBGT, time, and pre-cooling affected the $\mathrm{T}_{\text {shoulder }}$ results. Geldings showed, on average, a lower $\mathrm{T}_{\text {shoulder }}\left(-0.96^{\circ} \mathrm{C}, 95 \% \mathrm{CI}:-1.459,-0.459\right)$, older horses showed a higher average $\mathrm{T}_{\text {shoulder }}$ $\left(0.15^{\circ} \mathrm{C}, 95 \% \mathrm{CI}: 0.058,0.233\right)$ and higher WBGT values led to higher $\mathrm{T}_{\text {shoulder }}$ values $\left(0.14{ }^{\circ} \mathrm{C}, 95 \% \mathrm{CI}\right.$ : $0.082,0.199)$. Following pre-cooling, the horses showed, on average, a lower $\mathrm{T}_{\text {shoulder }}\left(-3.30^{\circ} \mathrm{C}, 95 \%\right.$ CI: $-3.739,-2.867$ ), and there were time effects (Figure 2, Supplementary Table S3).

\subsection{Rump Skin Temperature}

WBGT, day, time, and pre-cooling affected $\mathrm{T}_{\text {rump }}$. Higher WBGT values led to, on average, higher $\mathrm{T}_{\text {rump values }}\left(0.55{ }^{\circ} \mathrm{C}, 95 \% \mathrm{CI}\right.$ : $\left.0.463,0.645\right)$. $\mathrm{T}_{\text {rump }}$ was lower on the second testing day $\left(-1.39{ }^{\circ} \mathrm{C}, 95 \%\right.$ CI: $-1.958,-0.822)$. Pre-cooling caused, on average, a lower $\mathrm{T}_{\text {rump }}\left(-2.31^{\circ} \mathrm{C}, 95 \% \mathrm{CI}:-2.661,-1.967\right)$, and there were time effects (Figure 2, Supplementary Table S4).

\subsection{Plasma Lactate}

There was no effect of pre-cooling on $\mathrm{LA}_{0}$ (cooling: $1.7 \pm 0.6 \mathrm{mmol} / \mathrm{L}$; control: $1.6 \pm 0.3 \mathrm{mmol} / \mathrm{L}$ ) and $\mathrm{LA}_{10}$ (cooling: $0.8 \pm 0.1 \mathrm{mmol} / \mathrm{L}$; control: $0.9 \pm 0.1 \mathrm{mmol} / \mathrm{L}$ ).

\subsection{Sweating Response}

None of the factors affected GSL (cooling: $5.18 \pm 1.55 \mathrm{~L}$; control: $5.53 \pm 1.73 \mathrm{~L}$ ) and LSR on all three measurement locations and their corresponding sodium, chloride and potassium concentrations (Table 3). 
Table 3. Mean and standard deviation of the local sweating response and electrolyte concentrations at three skin sites of ten international eventing horses in the Netherlands during the warm-up and canter training following pre-cooling (cooling) or not (control) (average wet bulb globe temperature: $18.5 \pm 3.8^{\circ} \mathrm{C}$ ).

\begin{tabular}{|c|c|c|c|c|c|c|c|c|c|}
\hline \multirow{2}{*}{ Stage } & \multirow{2}{*}{ Skin Site } & \multicolumn{4}{|c|}{ Cooling } & \multicolumn{4}{|c|}{ Control } \\
\hline & & $\begin{array}{c}\text { LSR } \\
\left(\mathrm{mL} / \mathrm{m}^{2} / \mathrm{min}\right)\end{array}$ & $\begin{array}{l}\text { Sodium } \\
(\mathrm{mmol} / \mathrm{L})\end{array}$ & $\begin{array}{l}\text { Chloride } \\
\text { (mmol/L) }\end{array}$ & $\begin{array}{l}\text { Potassium } \\
(\mathrm{mmol} / \mathrm{L})\end{array}$ & $\begin{array}{c}\text { LSR } \\
\left(\mathrm{mL} / \mathrm{m}^{2} / \mathrm{min}\right)\end{array}$ & $\begin{array}{l}\text { Sodium } \\
(\mathrm{mmol} / \mathrm{L})\end{array}$ & $\begin{array}{l}\text { Chloride } \\
\text { (mmol/L) }\end{array}$ & $\begin{array}{l}\text { Potassium } \\
(\mathrm{mmol} / \mathrm{L})\end{array}$ \\
\hline \multirow{3}{*}{ Warming-up } & Neck & $7.6 \pm 3.3$ & $92.0 \pm 16.8$ & $152.9 \pm 28.8$ & $65.0 \pm 13.9$ & $6.8 \pm 4.7$ & $87.1 \pm 34.3$ & $148.0 \pm 43.6$ & $67.7 \pm 18.3$ \\
\hline & Barrel & $5.6 \pm 2.6$ & $105.1 \pm 23.9$ & $181.6 \pm 41.9$ & $57.7 \pm 17.5$ & $5.2 \pm 3.6$ & $91.4 \pm 21.4$ & $150.3 \pm 41.5$ & $68.6 \pm 12.0$ \\
\hline & Rump & $5.0 \pm 4.8$ & $109.0 \pm 23.4$ & $187.6 \pm 32.5$ & $76.3 \pm 7.4$ & $3.7 \pm 2.1$ & $77.6 \pm 40.8$ & $153.4 \pm 94.0$ & $67.3 \pm 43.0$ \\
\hline \multirow{3}{*}{$\begin{array}{l}\text { Canter } \\
\text { training }\end{array}$} & Neck & $13.0 \pm 3.6$ & $99.1 \pm 20.8$ & $137.8 \pm 46.1$ & $48.5 \pm 18.7$ & $14.1 \pm 4.7$ & $95.1 \pm 26.9$ & $132.2 \pm 43.6$ & $45.0 \pm 9.0$ \\
\hline & Barrel & $10.4 \pm 3.1$ & $89.0 \pm 16.7$ & $124.1 \pm 33.8$ & $43.3 \pm 15.8$ & $12.9 \pm 2.7$ & $102.8 \pm 17.9$ & $145.9 \pm 26.8$ & $51.1 \pm 9.5$ \\
\hline & Rump & $16.8 \pm 7.1$ & $77.6 \pm 39.3$ & $103.6 \pm 70.5$ & $35.9 \pm 29.0$ & $15.3 \pm 5.0$ & $102.8 \pm 29.8$ & $169.5 \pm 46.1$ & $66.1 \pm 16.1$ \\
\hline
\end{tabular}

LSR: Local sweat rate. 


\section{Discussion}

To our knowledge, this is the first study to assess the thermophysiological effects of pre-cooling on horses. Despite the moderate intensity exercise and moderate environmental conditions elicited, we observed rises in thermophysiological variables (Figure 2, Table 3). Most importantly, pre-cooling by cold-water rinsing directly after warming-up led to a smaller rise in $\mathrm{T}_{\text {re, }}, \mathrm{T}_{\text {shoulder, }}$ and $\mathrm{T}_{\text {rump }}$ during training compared to the control condition. These attenuated rises can be used to increase the margin for heat storage, allowing a longer exercise time before a critical $\mathrm{T}_{\mathrm{re}}$ (for horses most likely $\left.\mathrm{T}_{\mathrm{re}} \sim 41^{\circ} \mathrm{C}[1,4,28,29]\right)$ is reached. This may help to optimize equine welfare during eventing competitions and may potentially be beneficial for performance on the cross-country test, even in moderate environmental conditions. In addition, the environmental conditions and individual horse characteristics (like sex, age, and breed) should be taken into account as these affected $\mathrm{T}_{\text {re, }}, \mathrm{T}_{\text {shoulder }}$, and/or $\mathrm{T}_{\text {rump. }}$.

\subsection{Testing Day}

Minimal effects of testing day were expected because a cross-over design was used. However, for the second and warmer testing day (WBGT day 1: $15.9 \pm 0.4{ }^{\circ} \mathrm{C}$; day 2: $21.1 \pm 3.9{ }^{\circ} \mathrm{C}$ ), we found significantly lower HR and $\mathrm{T}_{\text {rump }}$ values but higher $\mathrm{T}_{\mathrm{re}}$ values (Supplementary Tables S1-S4). Based on visual observations, the lower HR appeared to be caused by the fact that the horses were more habituated to the situation the second time, which caused less arousal. The higher environmental temperature at the second testing day likely impaired the heat dissipation by the smaller temperature difference between the skin and environment, causing larger heat storage and consequently a higher overall $\mathrm{T}_{\mathrm{re}}$. It is plausible to assume that, on the cooler day, more heat was lost via skin conduction, heating up the skin.

In the present study, there was a (non-significant) difference between the testing days in GSL; $5.89 \pm 1.66 \mathrm{~L}$ at the second and warmer testing day and $4.83 \pm 1.83 \mathrm{~L}$ on day $1(n=10)$. This likely supported cooling the skin down and attenuating the rise in $\mathrm{T}_{\text {rump }}$. Such differences in physiological responses between testing days are not surprising considering previous equine research, concluding that the number of exertional heat illness cases was significantly higher when WBGT was $20-23.9^{\circ} \mathrm{C}$ ( $\sim$ day 2 of the present study) compared to $<20^{\circ} \mathrm{C}$ ( $\sim$ day 1 of the present study) [30].

In addition, physiological responses were compared in different environmental conditions $[4,17,28,31]$. McCutcheon et al. [17] concluded that LSR and sweat electrolyte concentrations were largely reflected by a higher environmental temperature $\left(20^{\circ} \mathrm{C}\right.$ to $\left.32-34^{\circ} \mathrm{C}\right)$. Likewise, Geor et al. [4] observed significantly higher rates of heat storage in hot-dry (WBGT: $24.6 \pm 0.3^{\circ} \mathrm{C}$ ) and hot-humid conditions (WBGT: $24.7 \pm 0.3^{\circ} \mathrm{C}$ ) compared to cold-dry conditions (WBGT: $16.6 \pm 0.2{ }^{\circ} \mathrm{C}$ ). Therefore, the $\sim 5^{\circ} \mathrm{C}$ difference in WBGT shown here, even in cool to moderate environmental conditions, can have a large effect on rates of heat storage in eventing horses at competition days or during moderate to intense training sessions.

Despite balancing the order of testing, such temperature-dependent observations should be taken into consideration when interpreting our results, which were collected on two days that differed regarding the environmental conditions. Interestingly, in previous research the required evaporation $\left(E_{\text {req }}\right)$ already exceeded the maximal evaporative heat loss $\left(E_{\max }\right)$ in cool-dry conditions (WBGT: $16.6 \pm 0.2^{\circ} \mathrm{C}$ ) [4]. By definition, this represents un-compensable heat stress. Assuming that the un-compensable heat stress also applies to the present study on both testing days, it is likely that the conditions were at least similar regarding compensability (i.e., the effectiveness of thermoregulation). From a practical point of view, this should be highlighted to eventing riders and trainers, as it is commonly believed that these conditions are not challenging for eventing horses.

\subsection{Thermophysiological Responses}

In the present study, the rise in $\mathrm{T}_{\mathrm{re}}$ during training was smaller following pre-cooling than without a pre-cooling strategy (control; Figure 2). As pre-cooling is intended to increase the margin for the rise 
in core temperature [20], our pre-cooling strategy appeared to be effective [1,32,33]. As expected, the largest absolute effect of pre-cooling was observed for both $\mathrm{T}_{\text {shoulder }}$ and $\mathrm{T}_{\text {rump }}\left(\sim 2-3{ }^{\circ} \mathrm{C}\right.$; Figure 2$)$, which is due to the cold-water rinsing of the skin. A larger difference between core and skin temperature allows for more heat dissipation by conduction, which may reduce heat strain [1]. The largest effect of the pre-cooling strategy on $\mathrm{T}_{\mathrm{re}}$, an indicator of core temperature, which is considered the critical determinant for performance in the heat [7], was only $1 \%$ or $0.3{ }^{\circ} \mathrm{C}$ here (Supplementary Table S2). Although, the normal $\mathrm{T}_{\text {re }}$ range of a horse is narrow (variation $\sim{ }^{\circ} \mathrm{C}$ [34]), from a physiological point of view, such a reduction in $\mathrm{T}_{\text {re }}$ may seem small. In particular, when considering that alongside pre-cooling, multiple factors, like environmental conditions, affected $\mathrm{T}_{\mathrm{re}}$ to the same extent.

However, only a few studies evaluated the horses under field conditions in a comparable situation where they actually train and compete. In relation to cooling methods, this may be important as the mass of the rider and saddle, and loss of cooling surface area due to the saddle can affect the thermophysiological responses of a horse [31]. In a field study by Hargreaves et al. [31], submaximal exercise in horses was evaluated in hot-humid $\left(\mathrm{HH}\right.$; environmental temperature $\left.31.3 \pm 0.9^{\circ} \mathrm{C}\right)$ and cool-dry $\left(\mathrm{CD} ; 17.6 \pm 0.4^{\circ} \mathrm{C}\right)$ circumstances. While in controlled laboratory settings, the environmental conditions largely affected the physiological parameters as discussed above, Hargreaves et al. [31] observed that, directly after cantering, $\mathrm{T}_{\mathrm{re}}$ was $39.0^{\circ} \mathrm{C}$ in $\mathrm{HH}$ and $38.5^{\circ} \mathrm{C}$ in $\mathrm{CD}$ conditions. In light of this relatively small $\mathrm{T}_{\text {re }}$ difference $\left(\sim 0.5^{\circ} \mathrm{C}\right)$ between conditions, lowering $\mathrm{T}_{\text {re }}$ by $0.3^{\circ} \mathrm{C}$ as in the present study may be physiologically relevant.

In another study by Marlin et al. [6] following high-intensity exercise in hot-humid environments, end-exercise $\mathrm{T}_{\text {re }}$ was $39.3 \pm 0.3{ }^{\circ} \mathrm{C}$, while simultaneously pulmonary artery temperature $\left(\mathrm{T}_{\text {pa }}\right)$ was $42.3 \pm 0.4{ }^{\circ} \mathrm{C}$. After the first 30-s post-cooling period (water temperature $\sim 6^{\circ} \mathrm{C}$ ), $\mathrm{T}_{\mathrm{pa}}$ decreased directly while $\mathrm{T}_{\text {re }}$ continued to increase (to $40.1 \pm 0.2{ }^{\circ} \mathrm{C}$ ). After $2 \mathrm{~min}$ of cooling, $\mathrm{T}_{\text {re }}$ showed a gradual decrease during the rest of the total cooling period of $6 \mathrm{~min}$ (end $\mathrm{T}_{\mathrm{re}} 39.3 \pm 0.3^{\circ} \mathrm{C}$, while end $\mathrm{T}_{\text {pa }}$ was $\left.38.2 \pm 0.2^{\circ} \mathrm{C}\right)$. The decreases correspond to $12{ }^{\circ} \mathrm{C} / \mathrm{h}\left(0.2{ }^{\circ} \mathrm{C} / \mathrm{min}\right)$ for $\mathrm{T}_{\mathrm{re}}$, while $\mathrm{T}_{\text {pa }}$ decreased with $0.8 \pm 0.1^{\circ} \mathrm{C} / \mathrm{min}$.

In a more recent study, five cooling methods in a hot-humid environment (WBGT temperature: $31.8 \pm 0.1^{\circ} \mathrm{C}$ ) were evaluated. These horses showed the largest decrease in $\mathrm{T}_{\mathrm{pa}}$ and $\mathrm{T}_{\mathrm{re}}$ using a shower method (tap water of $\sim 26^{\circ} \mathrm{C}$ for $30 \mathrm{~min}$ ), compared to the intermittent application of cold-water (16 L of $\sim 10^{\circ} \mathrm{C}$ water every $3 \mathrm{~min}$ for a total of $30 \mathrm{~min}$ ) [8]. When the horses were showered after the intense training session, $\mathrm{T}_{\text {re }}$ decreased from $39.7 \pm 0.6{ }^{\circ} \mathrm{C}$ to $38.6 \pm 0.4{ }^{\circ} \mathrm{C}$ in $30 \mathrm{~min}$. This is a decrease in $\mathrm{T}_{\text {re }}$ of $0.04^{\circ} \mathrm{C} / \mathrm{min}$, corresponding to a total decrease of $0.29^{\circ} \mathrm{C}$ after $8 \mathrm{~min}$ of cooling (which is the average pre-cooling time of the present study). Utilizing the showering method, $\mathrm{T}_{\text {pa }}$ decreased just below $39.0^{\circ} \mathrm{C}$ within $2.1 \pm 0.6 \mathrm{~min}$, and, after $9 \mathrm{~min}, \mathrm{~T}_{\text {pa }}$ decreased to baseline temperatures $\left(\mathrm{T}_{\mathrm{pa}} \sim 38^{\circ} \mathrm{C}\right)$. This would reflect a $\mathrm{T}_{\mathrm{pa}}$ decrease of $0.44^{\circ} \mathrm{C} / \mathrm{min}$.

In the study of Kohn et al. [10], where the horses were washed with cold-water post-exercise a $0.05^{\circ} \mathrm{C} / \mathrm{min}$ decrease in $\mathrm{T}_{\text {re }}$ was seen in the first $15 \mathrm{~min}$. At the same time, $\mathrm{T}_{\mathrm{pa}}$ decreased with a rate of $0.25{ }^{\circ} \mathrm{C} / \mathrm{min}$. The lag in reduction of $\mathrm{T}_{\text {re }}$ compared to $\mathrm{T}_{\mathrm{pa}}$ represents a delay in distribution of heat to peripheral body tissues or may reflect the heat of the hind limbs transferred to the rectum $[1,35]$. It is important for horse riders, trainers, and owners to understand that $\mathrm{T}_{\mathrm{re}}$ is not as indicative of the actual core temperature (i.e., temperature of the internal organs) as is sometimes assumed, due to the lag in $\mathrm{T}_{\text {re }}$. An increase in $\mathrm{T}_{\mathrm{re}}$ commonly corresponds to a larger increase in $\mathrm{T}_{\mathrm{pa}}$ and muscle temperature $[4,6,8,10]$, and this should be taken into account when predicting the core temperature and assessing heat strain in horses.

As shown in the studies mentioned above, post-cooling methods facilitate more heat dissipation compared to the conditions without cooling. Effective post-cooling methods appear to result in a $\mathrm{T}_{\mathrm{re}}$ decrease of between $0.04-0.2^{\circ} \mathrm{C} / \mathrm{min}[6,8,10]$. The present study was performed under field conditions and the horses were cooled prior to exercise instead of post-exercise, resulting in an increase in $\mathrm{T}_{\text {re }}$ as heat is still produced due to exercise. The cooling durations elicited in the abovementioned studies 
largely exceed the time available for pre-cooling horses at equestrians events. In addition, saddled horses have a restricted cooling surface area, compared to non-ridden horses.

Here, we observed an attenuated increase of $0.3^{\circ} \mathrm{C}$ following $\sim 8 \mathrm{~min}$ of pre-cooling $\left(\sim 0.04{ }^{\circ} \mathrm{C} / \mathrm{min}\right)$ in saddled horses compared to the control condition. This seemingly small difference in $\mathrm{T}_{\mathrm{re}}$ can still be biological effective, especially as it shows a similar cooling rate in $\mathrm{T}_{\mathrm{re}}$ compared to other post-cooling studies $[6,8,10]$. It would have been interesting to measure $T_{p a}$ in these horses as larger temperature effects are typically visible in $\mathrm{T}_{\mathrm{pa}}$ compared to $\mathrm{T}_{\mathrm{re}}$. Unfortunately this was not possible in these horses under field conditions. As there is evidence of a dose-response relationship between pre-cooling volume and ensuing physiological outcomes [36], future research should investigate a more aggressive pre-cooling type (i.e., larger volume or longer duration). Nevertheless, small reductions in heat strain could already help improve horse welfare during equestrian events.

On the other hand, as the potential thermophysiological benefit of pre-cooling may be relatively small, the advantages and disadvantages of pre-cooling should be considered carefully. The potential detrimental effects of pre-cooling could arise from counteracting the increase in muscle temperature, elicited by warming-up. Elevated muscle temperatures allow for increases in the muscle metabolism, that positively affect performance. However, a $\mathrm{T}_{\mathrm{re}}$ of $41{ }^{\circ} \mathrm{C}$ is the upper limit, at that moment muscle temperature is already much higher, and it is likely that muscle denaturation will occur $[37,38]$. This should absolutely be avoided at all times.

Pre-cooling may not be beneficial prior to short-duration exercise, which heavily relies on muscle metabolism. However, pre-cooling may be beneficial for longer-duration exercise ( $>5 \mathrm{~min})$, with a higher thermoregulatory burden. We observed a significant effect of pre-cooling on $\mathrm{T}_{\mathrm{re}}$ from 6 min into exercise (Supplementary Table S2) and the largest effect after $20 \mathrm{~min}$ of exercise, supporting this theory.

Anecdotal evidence indicates that in practice riders and trainers already pre-cool their eventing horses before the cross-country test, while others believe that pre-cooling causes myopathies and muscle cramps. Previous post-cooling studies have not observed muscle stiffness or discomfort of the horses [6,9]. Neither were any adverse effects of pre-cooling found during nor following this study. As core temperature is the main driver of sweating [19,39], the non-significant different GSL is most likely explained by the small differences in $\mathrm{T}_{\text {re }}$ during training following or without cooling (Figure 2). Locally, pre-cooling did not affect the sweat production or sweat composition (Table 3). Since LSR affects sweat composition [17] and was not different between conditions, this likely explains the absence of differences in sweat composition. Future research is still required to fully understand the thermophysiological impact of pre-cooling on horses.

\subsection{Exceptional Individual Responses}

Above, we mentioned that alongside pre-cooling, multiple other factors affected the parameters that we examined here. The individual horse is one of these factors. Following pre-cooling, one horse unexpectedly showed a higher $\mathrm{T}_{\mathrm{re}}$ compared to the control condition (Figure S1), whereas the other nine horses showed a response similar to the group average. Even though day-to-day variation in $\mathrm{T}_{\mathrm{re}}$ is a well-known phenomenon [17], the rise in $\mathrm{T}_{\mathrm{re}}$ during training was also comparable (cooling: $+0.50{ }^{\circ} \mathrm{C}$, control: $\left.+0.51^{\circ} \mathrm{C}\right)$. For this horse, the external $(\mathrm{V})$ and internal $\left(\mathrm{LA}_{0}\right.$ and $\left.\mathrm{LA}_{10}\right)$ workload indicators were similar between conditions. The pre-cooling protocol may not have affected thermoregulation in this horse (i.e., a poor responder). Considering the doseresponse relation of pre-cooling volume and ensuing physiological outcomes [36], it would have been interesting to investigate a more aggressive pre-cooling type (i.e., a larger volume of water). Secondly, one horse (a gelding, 13 years, and CCI4-5* level) had a final $\mathrm{T}_{\mathrm{re}}$ of $39.6{ }^{\circ} \mathrm{C}\left(+1.3^{\circ} \mathrm{C}\right.$ rise $)$ in the control condition, which is unexpectedly high considering the environmental conditions. The pre-cooling strategy was effective in reducing the end-exercise $\mathrm{T}_{\mathrm{re}}$ for this horse by $-0.5^{\circ} \mathrm{C}$. If this horse participates in events in more challenging conditions, $\mathrm{T}_{\text {re }}$ will potentially rise up to dangerous values, emphasizing the importance of collecting individual data regarding thermoregulatory profiling, as is recommended in humans [40]. 


\subsection{Limitations}

A significant limitation of the present study is that the environmental conditions on both testing days differed considerably, which is discussed in detail above. The researchers attempted to minimize the differences in environmental conditions by choosing sTable Summer weather. However, this will always be challenging in field studies. Another potential limitation may be that the findings only apply to moderate environmental conditions and exercise intensity used in the present study. The effect of pre-cooling on the measured variables may have been larger if a high intensity exercise protocol in hot and/or humid conditions was used [20]. However, we used privately-owned high-performance horses, and thus the circumstances had to be within acceptable limits. In addition, the included horses here all compete in the highest international eventing levels, and thus, were assumed to have high fitness levels. Previous research showed larger performance benefits of pre-cooling in humans with a high compared to a low aerobic fitness level [20]. Consequently, the benefit of pre-cooling could have been less in relatively unfit horses. Therefore, evaluating the effects of pre-cooling in an controlled and more challenging environment, at different exercise intensities and/or with horses of different levels of fitness, would be interesting for further research.

Considering the data collection, it would have been interesting to measure a closer indicator of the actual core temperature (i.e., the temperature of the internal organs) than $\mathrm{T}_{\text {re }}$. However, measuring the pulmonary artery $\left(\mathrm{T}_{\mathrm{pa}}\right)$ or muscle temperature was not feasible in this field study. Additionally, at equestrian events, $\mathrm{T}_{\text {re }}$ is commonly measured, allowing for an easy translation to practice. To further improve our understanding of the impact of pre-cooling on horses, future research should include a performance measure (i.e., the time to complete a certain distance) alongside a thermoregulatory observational part.

\section{Conclusions}

Pre-cooling horses by whole-body cold-water rinsing, directly before moderate intensity training, led to a slightly smaller rise in rectal and skin temperatures in moderate environmental conditions. Considering the relatively small, and late (after $6 \mathrm{~min}$ ), impact on the thermophysiological parameters, pre-cooling may be most beneficial in moderate- to longer-duration exercise with a high thermoregulatory burden, such as the cross-country test in the eventing discipline. Understanding the individual responses to pre-cooling is important for optimising welfare, and possibly improving performance during training and competition in challenging environmental conditions.

Supplementary Materials: The following are available online at http://www.mdpi.com/2076-2615/10/9/1664/s1. Table S1: Results of the final mixed model regarding heart rate. Table S2: Results of the final mixed model regarding rectal temperature. Table S3: Results of the final mixed model regarding shoulder skin temperature. Table S4: Results of the final mixed model regarding rump skin temperature. Figure S1: Deep rectal temperature response.

Author Contributions: Conceptualization, L.K., E.S., and C.M.; methodology, L.K., E.S., and C.M.; software, J.v.d.B.; formal analysis, L.K., J.v.d.B., and C.M.; investigation, L.K., E.S., M.F., N.G., and C.M.; resources, L.K. and C.M.; data curation, L.K., E.S., M.F., N.G., and C.M.; writing-original draft preparation, L.K. and C.M.; writing-review and editing, L.K.; visualization, L.K.; supervision, M.S.v.O.-O. and C.M.; project administration, M.S.v.O.-O. and C.M.; funding acquisition, C.M.; All authors have read and agreed to the published version of the manuscript.

Funding: This research was partly funded by Eurostars, grant number ESTAR 17213; The Dutch Research Council, grant number 690462 the Netherlands Organization for Health Research and Development, grant number 2019-30601; and partly by Moxie Sport, Lips Stables, Kluytmans Eventing, and the Utrecht veterinary faculty.

Acknowledgments: We wish to thank the horses and riders of Lips Stables and Ilonka Kluytmans for their participation.

Conflicts of Interest: The authors declare no conflict of interest. 


\section{References}

1. Hodgson, D.; McCutcheon, L.J.; Byrd, S.K.; Brown, W.S.; Bayly, W.; Brengelmann, G.; Gollnick, P. Dissipation of metabolic heat in the horse during exercise. J. Appl. Physiol. 1993, 74, 1161-1170. [CrossRef] [PubMed]

2. Marlin, D.J.; Harris, P.A.; Schroter, R.C.; Harris, R.C.; Roberts, C.A.; Scott, C.M.; Orme, C.E.; Dunnett, M.; Dyson, S.J.; Barrelet, F.; et al. Physiological, metabolic and biochemical responses of horses competing in the speed and endurance phase of a CCI ${ }^{* * * * 3-d a y-e v e n t . ~ E q u i n e ~ V e t . ~ J . ~ S u p p l . ~ 1995, ~ 27, ~ 37-46 . ~[C r o s s R e f] ~}$ [PubMed]

3. McCutcheon, L.J.; Geor, R.J. Thermoregulation and exercise-associated heat stress. In Equine Exercise Physiology, 1st ed.; Saunders: Philadelphia, PA, USA, 2008; pp. 382-396.

4. Geor, R.J.; McCutcheon, L.J.; Ecker, G.L.; Lindinger, M.I. Heat storage in horses during submaximal exercise before and after humid heat acclimation. J. Appl. Physiol. (1985) 2000, 89, 2283-2293. [CrossRef] [PubMed]

5. Hodgson, D.R.; Davis, R.E.; McConaghy, F.F. Thermoregulation in the horse in response to exercise. Br. Vet. J. 1994, 150, 219-235. [CrossRef]

6. Marlin, D.J.; Scott, C.M.; Roberts, C.A.; Casas, I.; Holah, G.; Schroter, R.C. Post exercise changes in compartmental body temperature accompanying intermittent cold water cooling in the hyperthermic horse. Equine Vet. J. 1998, 30, 28-34. [CrossRef] [PubMed]

7. Hargreaves, M. Physiological limits to exercise performance in the heat. J. Sci. Med. Sport 2008, 11, 66-71. [CrossRef] [PubMed]

8. Takahashi, Y.; Ohmura, H.; Mukai, K.; Shiose, T.; Takahashi, T. A comparison of 5 cooling methods in hot and humid environments in Thoroughbred horses. J. Equine Vet. Sci. 2020, 91, 103130. [CrossRef] [PubMed]

9. Williamson, L.; White, S.; Maykuth, P.; Andrews, F.; Sommerdahl, C.; Green, E. Comparison between two post exercise cooling methods. Equine Vet. J. 1995, 27, 337-340. [CrossRef]

10. Kohn, C.W.; Hinchcliff, K.W.; McKeever, K.H. Evaluation of washing with cold water to facilitate heat dissipation in horses exercised in hot, humid conditions. Am. J. Vet. Res. 1999, 60, 299-305.

11. Marino, F.E. Methods, advantages, and limitations of body cooling for exercise performance. Br. J. Sports Med. 2002, 36, 89-94. [CrossRef]

12. Casa, D.J.; McDermott, B.P.; Lee, E.C.; Yeargin, S.W.; Armstrong, L.E.; Maresh, C.M. Cold water immersion: The gold standard for exertional heatstroke treatment. Exerc. Sport Sci. Rev. 2007, 35, 141-149. [CrossRef] [PubMed]

13. Bongers, C.C.; Hopman, M.T.; Eijsvogels, T.M. Cooling interventions for athletes: An overview of effectiveness, physiological mechanisms, and practical considerations. Temperature 2017, 4, 60-78. [CrossRef] [PubMed]

14. Serrano, M.; Evans, D.; Hodgson, J. Heart rate and blood lactate responses during exercise in preparation for eventing competition. Equine Vet. J. 2002, 34, 135-139. [CrossRef] [PubMed]

15. Amory, H.; Art, T.; Linden, A.; Desmecht, D.; Buchet, M.; Lekeux, P. Physiological response to the cross-country phase in eventing horses. J. Equine Vet. Sci. 1993, 13, 646-650. [CrossRef]

16. Marlin, D.J.; Misheff, M.; Whitehead, P. Optimising Performance in a Challening Climate. In Proceedings of the Fédération Equestre Internationale (FEI) Sports Forum 2018, Lausanne, Switzerland, 26-27 March 2018; pp. 11-24.

17. McCutcheon, L.J.; Geor, R.J.; Hare, M.J.; Ecker, G.L.; Lindinger, M.I. Sweating rate and sweat composition during exercise and recovery in ambient heat and humidity. Equine Vet. J. Suppl. 1995, 27, 153-157. [CrossRef] [PubMed]

18. Kingston, J.K.; Geor, R.J.; McCutcheon, L.J. Rate and composition of sweat fluid losses are unaltered by hypohydration during prolonged exercise in horses. J. Appl. Physiol. 1997, 83, 1133-1143. [CrossRef] [PubMed]

19. Nadel, E.R.; Mitchell, J.W.; Saltin, B.; Stolwijk, J.A. Peripheral modifications to the central drive for sweating. J. Appl. Physiol. 1971, 31, 828-833. [CrossRef]

20. Wegmann, M.; Faude, O.; Poppendieck, W.; Hecksteden, A.; Frohlich, M.; Meyer, T. Pre-cooling and sports performance: A meta-analytical review. Sports Med. 2012, 42, 545-564. [CrossRef]

21. Von Elm, E.; Altman, D.G.; Egger, M.; Pocock, S.J.; Gøtzsche, P.C.; Vandenbroucke, J.P. The Strengthening the Reporting of Observational Studies in Epidemiology (STROBE) statement: Guidelines for reporting observational studies. Ann. Intern. Med. 2007, 147, 573-577. [CrossRef] 
22. Munsters, C.C.; van Iwaarden, A.; van Weeren, R.; Sloet van Oldruitenborgh-Oosterbaan, M.M. Exercise testing in Warmblood sport horses under field conditions. Vet. J. 2014, 202, 11-19. [CrossRef]

23. Morgan, E.K.M. Climatic energy demands of horses. Equine Vet. J. 1995, 18, 4. [CrossRef]

24. McCutcheon, L.J.; Geor, R.; Hare, M.J.; Kingston, J.K.; Staempfli, H. Sweat composition: Comparison of collection methods and effects of exercise intensity. Equine Vet. J. 1995, 27, 279-284. [CrossRef]

25. Siegers, E.W.; Sloet van Oldruitenborgh-Oosterbaan, M.M.; Van den Broek, J.; Munsters, C.B.M. Evaluation of three portable lactate-measurement devices in exercising horses. Pferdeheilkunde Equine Med. 2018, 34, 141-144. [CrossRef]

26. Feng, C.; Wang, H.; Lu, N.; Chen, T.; He, H.; Lu, Y.; Tu, X.M. Log-transformation and its implications for data analysis. Shanghai Arch. Psychiatry 2014, 26, 105-109. [CrossRef]

27. Lukacs, P.M.; Burnham, K.P.; Anderson, D.R. Model selection bias and Freedman's paradox. Ann. Inst. Stat. Math. 2010, 62, 117. [CrossRef]

28. Marlin, D.J.; Scott, C.M.; Schroter, R.C.; Mills, P.C.; Harris, R.C.; Harris, P.A.; Orme, C.E.; Roberts, C.A.; Marr, C.M.; Dyson, S.J.; et al. Physiological responses in nonheat acclimated horses performing treadmill exercise in cool (20 degrees C/40\% RH), hot dry (30 degrees C/40\% RH) and hot humid (30 degrees C/80\% RH) conditions. Equine Vet. J. Suppl. 1996, 70-84. [CrossRef] [PubMed]

29. McConaghy, F.F.; Hales, J.R.; Rose, R.J.; Hodgson, D.R. Selective brain cooling in the horse during exercise and environmental heat stress. J. Appl. Physiol. (1985) 1995, 79, 1849-1854. [CrossRef]

30. Takahashi, Y.; Takahashi, T. Risk factors for exertional heat illness in Thoroughbred racehorses in flat races in Japan (2005-2016). Equine Vet. J. 2020, 52, 364-368. [CrossRef] [PubMed]

31. Hargreaves, B.J.; Kronfeld, D.S.; Naylor, J.R. Ambient temperature and relative humidity influenced packed cell volume, total plasma protein and other variables in horses during an incremental submaximal field exercise test. Equine Vet. J. 1999, 31, 314-318. [CrossRef] [PubMed]

32. Geor, R.J.; McCutcheon, L.J.; Ecker, G.L.; Lindinger, M.I. Thermal and cardiorespiratory responses of horses to submaximal exercise under hot and humid conditions. Equine Vet. J. Suppl. 1995, 125-132. [CrossRef]

33. Green, A.R.; Gates, R.S.; Lawrence, L.M. Measurement of horse core body temperature. J. Therm. Biol. 2005, 30, 370-377. [CrossRef]

34. Piccione, G.; Caola, G.; Refinetti, R. The circadian rhythm of body temperature of the horse. Biol. Rhythm. Res. 2002, 33, 113-119. [CrossRef]

35. Kohn, C.W.; Hinchcliff, K.W. Physiological responses to the endurance test of a 3-day-event during hot and cool weather. Equine Vet. J. Suppl. 1995, 31-36. [CrossRef] [PubMed]

36. Minett, G.M.; Duffield, R.; Marino, F.E.; Portus, M. Volume-dependent response of precooling for intermittent-sprint exercise in the heat. Med. Sci. Sports Exerc. 2011, 43, 1760-1769. [CrossRef] [PubMed]

37. McGowan, C.J.; Pyne, D.B.; Thompson, K.G.; Rattray, B. Warm-Up Strategies for Sport and Exercise: Mechanisms and Applications. Sports Med. 2015, 45, 1523-1546. [CrossRef] [PubMed]

38. Brinnel, H.; Cabanac, M.; Hales, J. Critical upper levels of body temperature, tissue thermosensitivity and selective brain cooling in hyperthermia. In Proceedings of the CSIRO Division of Animal Production, Sydney, Australia, 27 April-1 May 1987; pp. 209-240.

39. Nadel, E.R.; Bullard, R.W.; Stolwijk, J.A. Importance of skin temperature in the regulation of sweating. J. Appl. Physiol. 1971, 31, 80-87. [CrossRef] [PubMed]

40. Corbett, J.; Rendell, R.A.; Massey, H.C.; Costello, J.T.; Tipton, M.J. Inter-individual variation in the adaptive response to heat acclimation. J. Therm. Biol. 2018, 74, 29-36. [CrossRef]

(C) 2020 by the authors. Licensee MDPI, Basel, Switzerland. This article is an open access article distributed under the terms and conditions of the Creative Commons Attribution (CC BY) license (http://creativecommons.org/licenses/by/4.0/). 